\title{
Correction to: Efficacy and acceptability of parent-only group cognitive behavioral intervention for treatment of anxiety disorder in children and adolescents: a meta-analysis of randomized controlled trials
}

Bangmin Yin ${ }^{1,2,3}$, Teng Teng ${ }^{2,3}$, Lyu Tong ${ }^{4}$, Xuemei Li ${ }^{2,3}$, Li Fan ${ }^{2,3}$, Xinyu Zhou ${ }^{5^{*}}$ and Peng Xie , $^{2, *^{*}}$

Correction to: BMC Psychiatry 21, 29 (2021)

https://doi.org/10.1186/s12888-020-03021-0

Following publication of the original article [1], the authors identified errors in Fig. 5 and Fig. 6. The correct figures are given below.

The author group has been updated above and the original article [1] has been corrected.

\section{Author details}

${ }^{1}$ Department of Neurology, People's Hospital of Deyang City, Deyang, China. ${ }^{2}$ Department of Neurology, The First Affiliated Hospital of Chongqing Medical University, Chongqing, China. ${ }^{3} \mathrm{NHC}$ Key Laboratory of Diagnosis and Treatment on Brain Functional Diseases, The First Affiliated Hospital, Chongqing Medical University, No. 1 Youyi Road, Chongqing 400016, China. ${ }^{4}$ Department of Immunology, College of Basic Medical Sciences, China Medical University, Shenyang, China. ${ }^{5}$ Department of Psychiatry, The First Affiliated Hospital of Chongqing Medical University, No. 1 Youyi Road, Chongqing 400016, China.
Published online: 16 February 2021

\section{Reference}

1. Yin, et al. Efficacy and acceptability of parent-only group cognitive behavioral intervention for treatment of anxiety disorder in children and adolescents: a meta-analysis of randomized controlled trials. BMC Psychiatry. 2021;21:29. https://doi.org/10.1186/s12888-020-03021-0.

*Correspondence: xinyu973@126.com; xiepeng973@126.com

${ }^{5}$ Department of Psychiatry, The First Affiliated Hospital of Chongqing Medical University, No. 1 Youyi Road, Chongqing 400016, China

${ }^{2}$ Department of Neurology, The First Affiliated Hospital of Chongqing Medical University, Chongqing, China

Full list of author information is available at the end of the article

(c) The Author(s). 2021 Open Access This article is licensed under a Creative Commons Attribution 4.0 International License, which permits use, sharing, adaptation, distribution and reproduction in any medium or format, as long as you give appropriate credit to the original author(s) and the source, provide a link to the Creative Commons licence, and indicate if changes were made. The images or other third party material in this article are included in the article's Creative Commons licence, unless indicated otherwise in a credit line to the material. If material is not included in the article's Creative Commons licence and your intended use is not permitted by statutory regulation or exceeds the permitted use, you will need to obtain permission directly from the copyright holder. To view a copy of this licence, visit http://creativecommons.org/licenses/by/4.0/ The Creative Commons Public Domain Dedication waiver (http://creativecommons.org/publicdomain/zero/1.0/) applies to the data made available in this article, unless otherwise stated in a credit line to the data. 


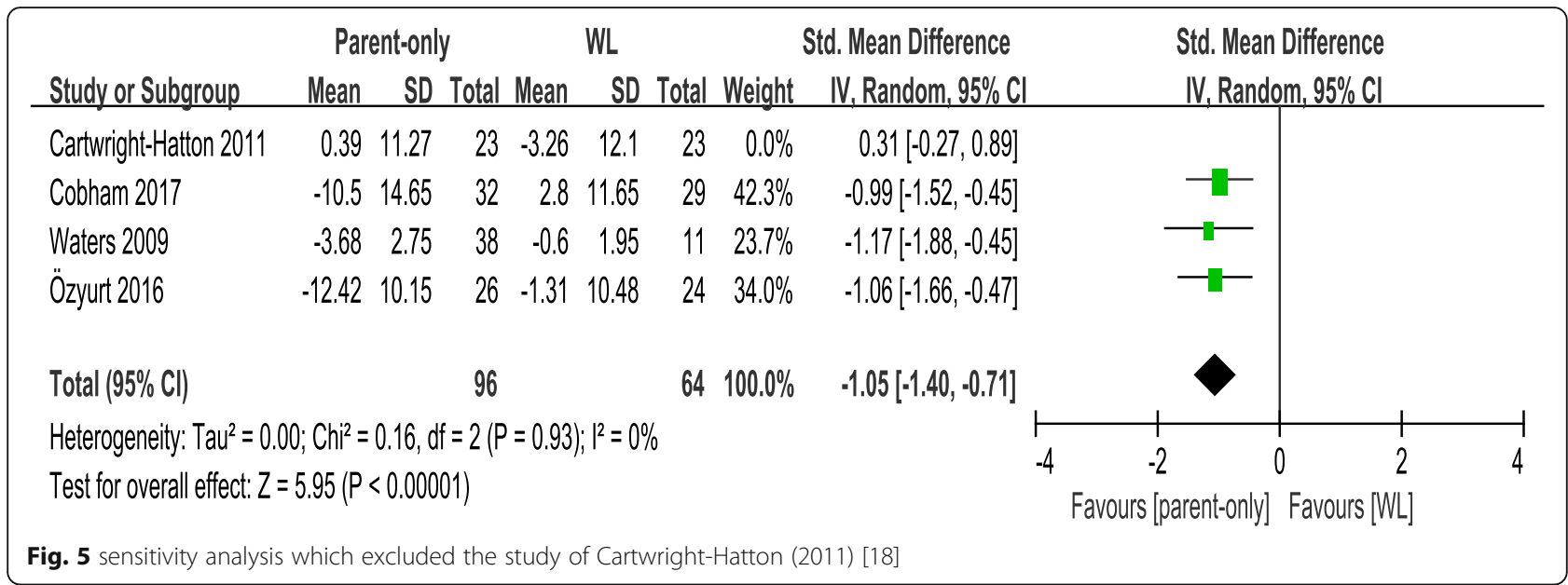




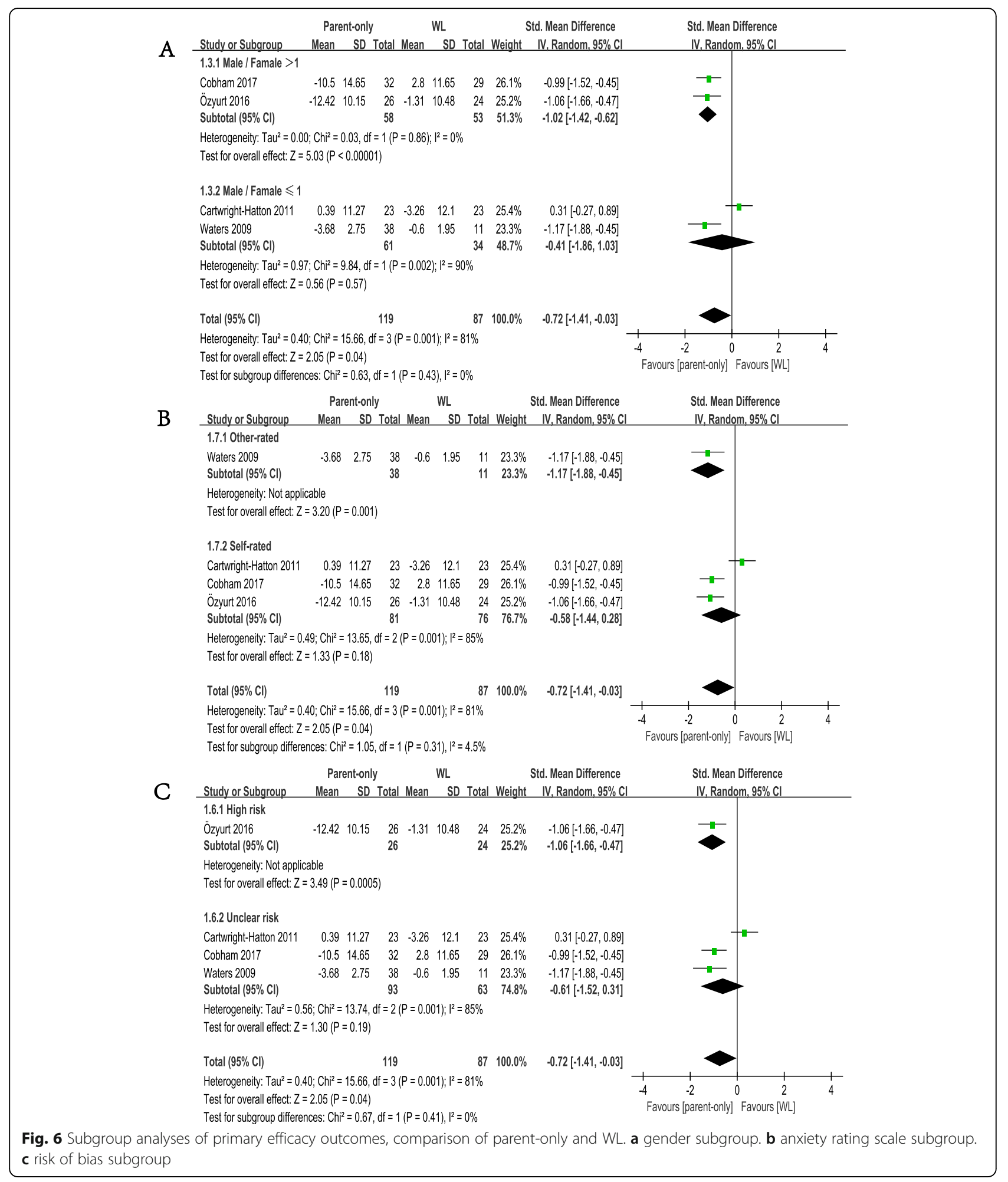

